\title{
El Consulado de Lima \\ y la política comercial española \\ frente a las coyunturas de cambio \\ de fines del periodo colonial (1806-1821) ${ }^{1}$
}

\section{Introducción}

Desde los primeros tiempos coloniales las relaciones entre la Corona española y la élite mercantil fueron muy estrechas. La reciprocidad era el elemento clave que vinculaba los intereses y beneficios de ambas partes y que brindó protección al sistema a lo largo de 300 años. El Estado español se caracterizaba por su flexibilidad en la aplicación de la ley, y la élite mercantil, a través de los distintos consulados, concedió préstamos y donativos a cambio de recibir beneficios especiales, especialmente el de mantener su exclusividad en el tráfico comercial. Todo esto se mantuvo hasta el advenimiento de la dinastía borbónica que quiso crear un Estado fuerte. No obstante, siguió necesitando del apoyo que le daba el gremio mercantil, la institución más fuerte económicamente hablando, y debió seguir con el sistema de concesiones y beneficios. Por otro lado, el fraude y el contrabando se manifestaron como problemas endémicos a lo largo de todo el periodo colonial.

En ese contexto, este ensayo tiene por objetivo mostrar cómo el sistema mercantil español estuvo impregnado de una flexibilidad y una capacidad de adaptación notables, es decir, cómo tomaba una doble actitud frente a coyunturas políticas internas y externas que se proyectaba como parte de la racionalidad mercantil de la época y no sólo como patrimonio de España. Mostraremos cómo el contrabando, acrecentado durante las guerras de fines del siglo XVIII, formó parte del sistema comercial internacional que trataba de sacar partido, sin prejuicio de las circunstancias; y que los comerciantes no dudaban en

Este trabajo ha sido realizado con documentación recabada en el Archivo de Indias, gracias a la beca de investigación que recibí a través de la Agencia Española de Cooperación Internacional. 
solicitar franquicias aduaneras. Estos eran elementos que integraban el juego de concesiones y beneficios que se ponían en práctica ante diferentes coyunturas políticas, por ejemplo la guerra, y que llevaron a la Corona a ceder constantemente frente a las necesidades propias y a las presiones externas. Describiremos, además, cómo las necesidades económicas llevaban a las autoridades españolas a negociar con firmas comerciales inglesas -tal es el caso que expondremos de la firma Gordon y Murphy- más allá de las situaciones políticas en las que ambas potencias estaban enfrentadas. $Y$ en el caso de los corsarios, éstos no dudaban en tomar una presa aunque existieran acuerdos comerciales entre las naciones. La Corona incluso llegó a permitir el comercio libre con Inglaterra. Frente a esta situación, el Consulado de Comercio de Lima se enfrentó a la política del Estado tratando de proteger sus intereses por sobre todo, y llevando a cabo por lo tanto una política de exclusividad frente a la flexibilidad de la Corona.

\section{Antecedentes}

El juego de concesiones y beneficios entre el Consulado y el Estado español había permitido que las relaciones se mantuvieran cordiales a lo largo de mucho tiempo. Pero cuando la Corona decidió implementar una serie de reformas con el objeto de concentrar los beneficios del comercio, el Consulado se opuso a ello, dado que pretendía retener las prerrogativas que recibía como clase eminentemente privilegiada.

Una de las reformas que tuvo mayor resistencia, a lo largo del siglo XVIII, fue la aplicación del reglamento para el libre comercio de 1778, que se implementó en el Perú en 1784, dado que la guerra con Inglaterra había retrasado su aplicación. En un informe elevado por el Consulado a la Corona, en 1790, dicha institución se quejaba, entre otras cosas, de la excesiva importación de productos: aun cuando la capacidad de consumo en el virreinato, durante el quinquenio 1786/ 1790, había sido de cinco millones de pesos anuales, se importaron 46 millones lo que produjo una saturación del mercado. ${ }^{2}$ El virrey Gil de Taboada y Lemos, por su parte, consideraba que las pérdidas pro-

2 Este informe, junto con las notas al margen y comentarios del virrey Gil de Taboada y Lemos ha sido publicado por Deustua Pimentel (1989: 42), quien analiza en forma detallada tanto los comentarios de la institución como los del propio virrey. 
ducidas no eran cuantiosas puesto que las mismas fueron compartidas por los mercaderes europeos (no habla de españoles), y que "dichos capitalistas" habían perdido, pero otros por el contrario se habían enriquecido, en palabras textuales: "que la fortuna de unos ha pasado al poder de otros".

En otra ocasión, el virrey Gil de Taboada y Lemos expresaba que el comercio libre había permitido "a todos adquirir los medios que antes estaban reservados sólo a los pocos que hacían el comercio [...]". En una palabra, los beneficios a los cuales estaba acostumbrado el gremio de comerciantes se habían ampliado a una mayor cantidad de beneficiarios.

Como vemos, las relaciones de poder entre el Consulado y el Estado no eran ya tan cordiales como lo habían sido anteriormente. Con los Borbones dichas relaciones comenzaron a deteriorarse, debido al interés del rey de concentrar los mayores beneficios en el Estado.

Con respecto a las quejas de los comerciantes a través del Consulado, trabajos puntuales sobre grandes mercaderes, realizados en los últimos años, permiten demostrar que éstas constituyeron generalmente posturas tomadas frente al Estado, cuando en realidad dichos comerciantes no dejaron de tener el control del comercio desde su posición privilegiada en Lima (Mazzeo 1994 y 1998). Allí se encontraba el puerto principal, el Callao, por donde salía e ingresaba toda la mercadería que luego se distribuía en el virreinato del Perú; allí estaba asentada la élite mercantil que controlaba el circulante y que tenía los contactos en Cádiz para realizar los grandes negocios. Es cierto que, con las reformas borbónicas, Buenos Aires pasó a ser cabeza de virreinato y su puerto comenzó a tener mayor preeminencia. Pero, en realidad, tan sólo se legalizó una situación que venía de antaño y no fue este hecho el que perjudicó al comercio de Lima. Desde mediados del siglo XVIII (1749 y 1761), debido a las mercaderías que desde el Río de la Plata llegaban a la zona de Potosí a menores precios existían quejas por parte del virrey del Perú, por las que se solicitaba que se limitaran los ingresos por esa zona (Segreti 1987). ${ }^{3}$

La rivalidad entre Lima y Buenos Aires provenía desde el siglo XVII debido a la autorización de navíos de registro que llegaban al Río de la Plata, con hierro, muy necesario para la explotación minera del Alto Perú. 


\section{El comercio neutral}

La guerra con Inglaterra, iniciada en 1797, cambió las relaciones de poder al permitir el comercio con extranjeros y condujo a la total desarticulación del sistema mercantil. El comercio con neutrales provocó muchas transgresiones y desórdenes, razón por la cual la Corona ordenó suspender la medida a los dos años de promulgada. No obstante, se hizo caso omiso de dicha prohibición, y tanto las autoridades españolas como las británicas, y en algunos casos también las americanas -especialmente en el Río de la Plata- permitieron dicho comercio debido a las interesantes ganancias que dejaba (Malamud 1987: 301). Frente al comercio con neutrales fue el mismo virrey quien se opuso, especialmente durante la época de Avilés. No obstante, hay referencias concretas de que los comerciantes peruanos preferían trabajar con neutrales, debido a que sus fletes eran menores y combinaban los permisos otorgados por la Corona con privilegios especiales (Mazzeo 1998: 131-145).

La situación política internacional, especialmente la guerra con Francia, había precipitado la inflación y el gobierno se vio en la necesidad de implementar ciertas medidas para obtener mayores ingresos. La Caja de Consolidación se había creado como medio de recoger los capitales procedentes de la venta forzosa de las fincas de las instituciones religiosas, realizada tanto en España como en América. Este dinero recaudado por las ventas de bienes raíces llegaba a España para hacer frente a las necesidades de la guerra. Para transferir esos fondos, la Caja de Consolidación vendía libranzas contra cajas americanas (como cajas de censos comunales) al interés del 5\% a sociedades y compañías mercantiles, que luego se hacían efectivas mediante expediciones neutrales (Parrón Salas 1995: 456).

\section{Una empresa extranjera domina el comercio neutral}

Dentro del marco del comercio con neutrales existía un contrato desde 1806 entre Madrid y la casa de comercio Gordon y Murphy, de Londres, para llevar mercaderías a Veracruz, Caracas, Cartagena y Perú y demás posesiones españolas. Este contrato fue firmado por Juan Murphy en representación de la casa, como también con los señores Reid, Irving y Compañía, igualmente de Londres, y Manuel Sixto Espinosa, ministro de la Junta de Comercio de la Comisión de Consoli- 
dación de Vales Reales, nombrado el 6 de mayo de 1806 y ratificado en Londres el 14 de julio del mismo año. ${ }^{4}$ En el artículo 20 se establecía que, en caso de hacerse la paz con Inglaterra, sólo se realizarían las expediciones comenzadas tanto en los puertos neutrales como españoles y sólo se llevarían a cabo aquellas facturas que se hubieran presentado a los cónsules respectivos o transacciones que ya estuvieran navegando. Esto implica que era una negociación momentánea.

Esta negociación estaba encuadrada en las concesiones otorgadas a compañías y particulares y el contrato consistía en el transporte por cuenta de dicha casa de 30.000 quintales de azogue y 150.000 resmas de papel para cigarros, además del papel sellado, bulas y naipes y el retorno del puerto de Veracruz, La Habana, Cartagena y cualquier otro americano de diez millones de pesos fuertes. Los barcos navegarían con pabellón neutral, pero llevarían pasavantes ${ }^{5}$ ingleses. Al parecer, la intención de la Corona, especialmente de Godoy, quien se mostraba vacilante respecto al comercio americano con neutrales, era acercarse a Inglaterra y de esa manera zafarse del dominio de Napoleón en la política española (Ortiz de la Tabla 1978: 333).

En 1808 el rey de Inglaterra, Jorge III, expidió en la Corte de Saint James una especie de autorización para hacer saber a todos los comandantes de guerra y barcos particulares armados en corso que debían permitir a la firma Gordon y Murphy trasladar el navío Amelia al mando del capitán Juan Jennings, desde el puerto de Londres al de San Sebastián de Guipúzcoa, para tomar allí una porción de botellas de fierro vacías e introducirlas a Cádiz - a pesar del bloqueo decretado por Napoleón- en donde debía embarcar azogues y toda clase de efectos y manufacturas, fierros, acero y otras mercancías, con excepción de los de contrabando, y dirigirse a cualquier puerto americano. El barco, a su vez, debía retornar de algún puerto de América a algún puerto británico con carga de toda clase de productos americanos y con plata consignada a Gordon y Murphy o a sus agentes. Es decir que pedía a los corsarios que no molestaran ni pusieran dificultad alguna a los viajes de dicho barco, tanto a la ida como a la vuelta, siempre y

4 Contratas de Gordon y Murphy con el gobierno de España, AGI, Indif. Gen. 2473.

5 Los pasavantes eran documentos que daba a un buque el jefe de las fuerzas navales enemigas para que no fuera molestado en el mar. Era un especie de salvoconducto. 
cuando no hiciera un rumbo distinto al viaje permitido. Y este "pasavante" tenía una validez de un año. ${ }^{6}$ Pero esto no siempre se cumplió como veremos más adelante. Las transacciones a cargo de este consorcio Gordon y Murphy tenían como objetivo asegurar el funcionamiento de la maquinaria fiscal a gran escala e impedir que la economía quedase reducida a la mínima expresión y que se mantuvieran los flujos de plata remitidos a la Corona (Marichal 1999: 212).

No obstante dicho contrato, existen muchas reclamaciones por parte de la firma inglesa porque las negociaciones no pudieron llevarse a cabo debido a la oposición de los Consulados. En Veracruz, por ejemplo, no se permitió el desembarco de las fragatas Juan e Isabel con mercaderías por un millón de pesos. En 1811, 1816 y 1817, hubo repetidas reclamaciones por parte de dicha firma, las cuales se llevaron a cabo en Madrid, insistiendo en que debían introducirse en el puerto de Veracruz los efectos en los mismos términos expuestos anteriormente. Por lo tanto, se decidió que en el término de un año se despachasen desde Londres a Veracruz cinco buques españoles cargando cada uno de ellos géneros y efectos por valor de 200.000 pesos como equivalente del millón de pesos. Al no resolverse el problema, se decidió dividirlas en envíos menores de 100.000 pesos cada uno a cualquier puerto y en buques extranjeros para evitar el ataque de los corsarios. La plaza de Veracruz se encontraba abatida por los atrasos en la llegada de las embarcaciones. Sólo llegaron las fragatas Victoria, Proteo y Proserpina. ${ }^{7}$ ¿Qué era lo que impedía realizar estas ventas? Evidentemente los intereses de las élites mercantiles coloniales se veían perjudicadas, pues los beneficios iban a los extranjeros y no a ellos.

En el contrato original, firmado en 1806, se establecía, por ejemplo, que los algodones debían quedar libres del derecho de internación y también se estipulaba que la comercialización se haría entre los puertos de Veracruz y La Habana, y que en Europa los puertos habilitados serían Bremen y Hamburgo. Nuevamente hubo un rechazo al cumplimento de éste, por lo cual se nombraron los respectivos jueces o árbitros, uno por el gobierno español, otro por la casa comercial y

Autorización, Saint James, 30 de enero de 1808, AGI Indif. Gen. 2473.

Nota de Gordon y Murphy, 7 de junio de 1811, AGI, Indif. Gen. 2473; Nota de Martín de Garaya, virrey de Nueva España, Madrid, 22 de julio de 1817, ibid. Las razones que daban los ministros reales eran que se había dado la paz con Inglaterra y ya no eran necesarias las ventas con neutrales. 
otro por ambas partes, para que decidieran lo que correspondía sobre la liquidación de las cuentas y para determinar el aforo que habría de darse a los algodones.

La casa comercial Gordon y Murphy negociaba con los principales puertos coloniales y americanos y ponía en contacto a comerciantes de Inglaterra, España, Buenos Aires, Veracruz, Filadelfia y Lima. Con esta última, el eslabón en las negociaciones fue la familia Lavalle. En ocasión de llevar cacao, cascarilla y cobre desde el puerto del Callao a Europa, en el navío Amelia, la embarcación fue apresada por corsarios ingleses a la altura de las islas Canarias. El sobrecargo debió embarcarse para Lisboa y desde allí pasar a Londres, donde a través de Gordon y Murphy logró poner la expedición en libertad luego del pago de una franquicia por valor de 35.000 libras esterlinas. La cascarilla quedó en Londres para su venta y se dejaron libres el cacao y el cobre para venderlos en Cádiz, lo cual posiblemente se hiciera por Lisboa dado que Napoleón tenía bloqueado el puerto español (Mazzeo 1998: 131-145).

En otra oportunidad se concertó con Antonio de Lavalle -otro hijo radicado en Cádiz- enviar a Lima la fragata norteamericana Monticello con un cargamento de 50.000 pesos en mercaderías a los precios y plazos corrientes en plaza, cuyo despacho correría por cuenta de Lavalle, quien a su vez debería conseguir el flete más favorable. Pero esta negociación no llegó a feliz término, dado que la firma al parecer se quedó con las comisiones que les pertenecían a la familia Lavalle. ${ }^{8}$ Evidentemente Gordon y Murphy no cumplían con el pertinente pago a sus comisionados.

Pero, por otro lado, también había reclamaciones por parte de dicha casa comercial. En 1812, en Madrid, se comunicaba que se habían embargado los fondos pertenecientes a la casa Gordon y Murphy para cubrir los créditos pendientes a favor de la Real Hacienda y la Caja de Consolidación, la que, como hemos mencionado, había vendido libranzas a compañías extranjeras contra cajas americanas. En 1822 se hablaba del injusto procedimiento llevado a cabo tanto en México como en La Habana de embargar todos los bienes y propiedades de la casa Gordon y Murphy dado que suponían que era deudora de cuan-

8 Carta de Juan Bautista de Lavalle a su hermano radicado en Cádiz, 26 de noviembre de 1805, Archivo privado de la familia Lavalle. 
tiosas sumas a la hacienda pública. ${ }^{9}$ Dicha casa reclamaba derechos por los perjuicios provocados por el impedimento de las transacciones por un valor de 37.200 .000 reales de vellón. ${ }^{10}$

En el caso de México, la firma fue la intermediaria en la comercialización entre Jamaica y los puertos de Veracruz y La Habana. En ocasiones, la modalidad que utilizaban era el sistema de "rescates" de presas, algo similar a lo que usaron con la fragata Amelia y los productos peruanos. El Consulado de Veracruz se lamentaba muchísimo, pues los efectos introducidos por la casa Gordon y Murphy habían afectado tanto a la industria europea, principalmente a la de Cataluña, como a la americana, ya que se había permitido la extracción de plata hacia Inglaterra aun estando en guerra. ${ }^{11}$

En el caso del Perú, al parecer sólo se realizaron las negociaciones con la familia Lavalle. No obstante, la plaza de Lima estaba saturada, especialmente con tejidos de algodón que habían "entrado desde Asia y cuyas telas de muy mala calidad eran preferidas por la gente debido a su bajo costo a pesar de su poca duración". ${ }^{12}$

En Cádiz la situación no era mejor: en 1808, la plaza presentaba un aspecto melancólico, debido a que los almacenes estaban atestados de frutos coloniales sin salida y sólo se podía comerciar con Inglaterra, donde los frutos coloniales eran más apreciados. ${ }^{13}$ Es por ello que tanto el Consulado de Lima como el de Cádiz habían reaccionado contra el comercio neutral (Parrón Salas 1995: 462-471).

Vemos nuevamente la doble política de la Corona. Por un lado, el comercio con extranjeros afectaba las plazas comerciales virreinales tanto de Lima como de México; pero, por otro lado, el Estado español se veía obligado a no interrumpir el tráfico. Además teóricamente se debían recaudar importantes impuestos aduaneros. Los impuestos que

9 Documento firmado por Gordon y Murphy, Palacio, 23 de marzo de 1822, AGI, Indif. Gen. 2472.

10 Nota de Gordon y Murphy a la Junta de Hacienda de Indias, 31 de mayo de 1815 , AGI, Indif. Gen. 2473.

11 Ortiz de la Tabla (1978: 332-334) desarrolla ampliamente el comercio con neutrales y destaca la importancia de esta casa en las relaciones comerciales entre la Habana y Veracruz.

12 Carta de Juan Bautista de Lavalle a su hermano, 8 de enero de 1808, Archivo privado de la familia Lavalle.

13 Carta a Juan Bautista de Lavalle, Cádiz, 1 de octubre de 1808, Archivo privado de la familia Lavalle. 
debían pagar los extranjeros eran $21 \%$ a la entrada en España (rentas generales $15 \%$; para la Caja de Consolidación $5 \%$ y Consulado $1 \%$ ) y $9 \%$ a la salida para América (7\% derecho real; $1 \%$ subvención y $1 \%$ Consulado). En las aduanas americanas debían pagar lo estipulado por el decreto del libre comercio de 1778: almojarifazgo 7\%; alcabala $3 \%$; Consulado $1 \%$. Es por ello que se siguieron entregando franquicias a extranjeros, puesto que las necesidades obligaban a buscar soluciones de cualquier índole y las mercaderías no dejaron de ingresar a través de los barcos neutrales o mediante alguno de los mecanismos del comercio ilícito, como arribadas forzosas, comisos, remates y otros artilugios que veremos más adelante. El objetivo final se cumplía con la anuencia de los mismos funcionarios que en ocasiones participaban como simples comerciantes furtivos. ${ }^{14}$ En consecuencia, los caudales peruanos eran absorbidos por otros países europeos.

En resumen, la casa Gordon y Murphy tenía la concesión real de realizar el tráfico de mercaderías con las colonias americanas y a su vez contrataba con distintos comisionados. Para el Perú el nexo fue la familia Lavalle y al parecer no hubo negociaciones con otras firmas. Utilizaban embarcaciones norteamericanas para llevar la harina de Estados Unidos a La Habana y algodones a México. Asimismo, extraían metales y transportaban cacao y cascarilla desde Perú a Europa. El rechazo por parte del Consulado de Veracruz fue mayor debido a la saturación del mercado, especialmente con el ingreso de algodones asiáticos. En el Perú, en cambio, estas negociaciones estaban limitadas a un grupo muy privilegiado de comerciantes asentados en Lima.

El tráfico con neutrales no se limitó a los comerciantes ingleses, puesto que desde 1795 existía un Tratado de Amistad, Límites y Navegación entre España y Estados Unidos, por el cual multitud de balleneros frecuentaron los puertos de Chile y el Callao. Aunque el Consulado de Lima sospechaba que se trataba en realidad de corsarios ingleses. Compraban tantas cantidades de insumos que incluso disparaban los precios, y por esa razón el Consulado solicitó la prohibición de su entrada en los puertos del Pacífico, excepto en el Callao donde se comprobarían sus papeles y los que realmente llegaban de Boston

14 Moutoukias (1988) expone los mecanismos de ingreso ilícito que se utilizaban para el caso de Buenos Aires, que fueron los mismos usados para otras partes como se advierte en este artículo. 
serían atendidos y los sospechosos detenidos (Parrón Salas 1995: 462471).

El comercio con neutrales en el Perú no tuvo las repercusiones que se dieron en otras áreas americanas. Su ubicación geográfica actuaba como elemento protector. Las solicitudes para comerciar con países extranjeros no tuvieron mucho éxito, salvo las solicitadas por el conde de Premio Real, José Antonio de Lavalle, para comerciar negros (Mazzeo 1994). Otro comerciante que tuvo una interesante participación en el comercio con Lima fue Javier María de Aguirre, quien contó con amplio apoyo de la élite vinculada al Consulado: los hermanos Elizalde, el conde de Fuente González, el conde del Villar de Fuentes y Martín de Osambela, quienes solicitaron una licencia para importar 400.000 pesos de mercancías desde puerto neutral y también desde Cantón o Manila. Sin embargo, esta negociación no se llevó a cabo porque el comercio con el Oriente estaba prácticamente controlado por la Compañía de Filipinas, que estaba autorizada a ingresar 500.000 pesos anuales de mercaderías (Parrón Salas 1995: 437).

El comercio con neutrales no limitó la acción de los corsarios, quienes no dudaban en aproximarse a las costas del Perú en su afán de obtener ventajas de dicho comercio. Muchas son las referencias a la situación creada en el Pacífico Sur por los corsarios ingleses a principios del siglo XIX. El contrabando, junto con el comercio con neutrales, desarticuló totalmente el comercio con Cádiz. A continuación, describiremos algunas de las acciones llevadas a cabo por los ingleses.

\section{El contrabando en el Pacífico Sur}

Este era un problema endémico para la Corona española y al virreinato del Perú. Cien años antes, en 1704, habían llegado tanto comerciantes ingleses como franceses, en cuyas negociaciones estaba implícitamente comprometido el Consulado de Lima. Los comerciantes limeños compraban a los franceses tanto en el puerto del Callao como en Pisco mercaderías extranjeras y pagaban con plata. Esto ofrecía una doble ventaja: no sólo se podían comprar mercaderías más baratas, sino también vender las piñas de plata a un mejor precio. En ocasiones, esto provocó el enfrentamiento entre las autoridades virreinales a través de la Audiencia y el Consulado de Lima. Ambos bandos se acusaban mutuamente de estar implicados en el contrabando francés. 
Trabajos de Malamud (1986: 195-198) y de Walker (1979: 100-200) dan cuenta de los mecanismos y de la "doble vida" que los comerciantes de Lima llevaban, por un lado comerciando ilegalmente, y por otro, como corporación, condenando el contrabando.

A cien años de distancia, las cosas no habían cambiado demasiado, al Pacífico Sur llegaban embarcaciones, ya no francesas pero sí inglesas, que intentaban con una serie de artimañas introducir mercaderías y apropiarse de los productos regionales. Las condiciones políticas internacionales, la extensa costa peruana, y la situación crítica del erario ayudaban a la proliferación de acciones ilegales. Describiremos a continuación algunos casos.

En 1804 el bergantín inglés Harrington, procedente de Bengala, apresó al bergantín San Antonio de Padua del comercio de Chile, cerca del puerto de Coquimbo, y se apoderó de los 4.000 quintales de cobre que llevaban a cuenta del rey. Para restituir el cobre pedía un rescate de 6.000 pesos. $^{15}$

En Talcahuano los balleneros hacían caso omiso de aquel gobierno. Otras dos fragatas inglesas fondearon el 27 de octubre de 1804 en el puerto de Pisco y sus capitanes saltaron a tierra pidiendo víveres y, ante la negativa de sus habitantes, volvieron al día siguiente con gente armada y tomaron por la fuerza lo que necesitaban. ${ }^{16}$ También se acercaban a las costas del Río de la Plata por lo que se envió una carta al gobernador Pedro Cevallos, para que proporcionase los medios para evitar graves perjuicios.

En las costas de Chile, en 1809, se produjo un enfrentamiento entre una nave inglesa y otra española. La fragata Hero estaba fondeada en la Lengua de Baca, cerca al puerto de Coquimbo y, luego de un combate que duró tres horas, se rindió y fue apresada. Por los papeles de la Hero, así como por las declaraciones de sus oficiales, se llegó a saber que dicha fragata había sido armada en corso y traía mercancía de Juan y Guillermo Jacob, comerciantes de Londres. La fragata salió en 1807 con las licencias para hacer el contrabando en los mares del Sur, importando su cargamento facturas por 26.149 libras y diez chelines que habían resultado de las negociaciones clandestinas; por esto

15 Nota elevada al virrey sobre el apresamiento de la fragata Francisco de Paula, AGI, Estado 73.

16 Documento sobre el exceso de naves extranjeras, AGI, Estado 73, doc. 2. 
se encontraron a bordo oro y plata sellada y en pasta, como así también alhajas. La Junta de Marina del apostadero del Callao de Lima, como era costumbre, adjudicó íntegramente el cargamento a los apresadores, de acuerdo a la ordenanza de corso y dio cuenta de ello al virrey con los testimonios correspondientes. Se pasó también oficio al presidente de Chile a quien correspondía la indagación y castigo de los cómplices de contrabando. ${ }^{17}$

Era común que miembros de la burocracia virreinal estuvieran en connivencia para llevar a cabo el contrabando. Pero en este caso, debido a que en dicha fecha las alianzas se habían invertido y ahora España era aliada de Inglaterra y enemiga de Francia, "en atención a la buena armonía y relaciones íntimas de amistad y alianza e interés común" que reinaban entre ambas potencias, se decidió que los oficiales detenidos se pusiesen en libertad y se los remitiera en la primera ocasión a alguna colonia inglesa o portuguesa de América. Los comerciantes, a su vez, habían sido retenidos en Cádiz y no era la primera vez que realizaban estos hechos. Anteriormente, con la fragata corsaria Escorpión, habían practicado el contrabando en Quilimari cerca de Chile. La casa Jacob era conocida por su abierta profesión del contrabando. Tenía infestado el mar del Sur y corrompidos a los comerciantes de dicha costa. Incluso había ofrecido al gobierno llevar expediciones mercantes al Perú y Chile, bajo la seductora oferta de proporcionar fusiles para la guerra que mantenían con Francia. ${ }^{18}$ En una palabra, Inglaterra proporcionaría armas como compensación por la obtención del libre comercio con América.

España tenía ahora una nueva aliada, sin embargo, ello no impidió que el contrabando siguiera su propia dinámica. En 1809 había llegado a Río de Janeiro la fragata inglesa Higginson Senior, cuyo capitán era Sinclair Halerow, con intención sin duda de pasar al Pacífico debido al rico cargamento que llevaba y las porfiadas gestiones que realizaba el sobrecargo para dirigirse a Lima. De esa manera, el contraalmirante inglés se hizo nombrar correo marítimo y obtuvo de la princesa Joaquina y de su primo don Pedro un pasaporte y real permiso para llevar toda clase de efectos y mercancías a los puertos del Perú y

17 Expediente sobre el apresamiento de la fragata inglesa, 20 de noviembre de 1809 , AGI, Lima 1474.

18 Expediente enviado al virrey del Perú firmado por Esteban Fernández de León, 25 de octubre de 1807, AGI, Lima 1474. 
Chile, así como de extraer de ellos libremente, a su vuelta, oro, plata y demás producciones y frutos. A lo cual se agregaban que debían solicitar al virrey y autoridades competentes "brindar toda la protección y auxilio de acuerdo al tratado de paz a que las Juntas de España habían concluido con el gobierno británico con motivo de las usurpaciones llevadas a cabo por el enemigo común Napoleón". En el Perú, el virrey no estaba en modo alguno interesado en dar apoyo a esta negociación. Se reunió con el arzobispo y el Ayuntamiento y acordaron que no había lugar a la gracia solicitada, dado que esto era opuesto a las leyes de Indias que prohibían el comercio con extranjeros aunque fueran amigos y aliados. El tratado de paz firmado en 1808 entre ambos países establecía en el artículo 3, "que ni las autoridades aun de la misma familia real podrían hacer lícita la infracción de las leyes". Por supuesto que el sobrecargo Federico Douling no aceptó la decisión y, por el contrario, ofreció un donativo gratuito de $60 \mathrm{mil}$ duros e hizo una representación de cuánto ganaría la Real Hacienda en el cobro de los cuantiosos derechos de entrada de los efectos. Esta propuesta se rechazó y la fragata tuvo que dejar el puerto del Callao. No obstante, al parecer, la Audiencia entorpeció la partida para aprovecharse del menor descuido de los subalternos para la ejecución del contrabando.

Y parece ser que el oidor José Baquíjano, a quien la princesa del Brasil escribió por separado, había sido el promotor de dicha apelación e incluso se habla de que había ocultado en Lima por algunos días a los referidos capitán y sobrecargo. En este hecho es evidente el enfrentamiento entre la Audiencia y el virrey. Era la época de Fernando de Abascal, marqués de la Concordia, quien puso mucho celo en no permitir el comercio con extranjeros. La Audiencia se quejaba de que el virrey no aceptara la apelación referida. La situación terminó como sucedía en estos casos: la fragata Higginson se quedó en el puerto retrasada porque necesitaba hacer algunos arreglos y se le prestaron los auxilios requeridos cuyos gastos ascendieron a unos 535 pesos; pero, con el pretexto de que no tenían dinero y que el virrey no les había permitido vender nada de sus efectos, se fueron sin pagar. ${ }^{19}$

En realidad había dos tipos de comercio, uno legal y otro ilegal, que se llevaban a cabo en forma simultánea, como si fueran dos caras de una misma moneda: una visible y otra solapada. Dos políticas, una

19 Ibidem. 
establecida por las leyes de Indias y otra establecida por la necesidad, cuya característica era la adaptabilidad y la flexibilidad, porque la Corona, a pesar de aceptar en pactos y tratados el comercio con Inglaterra, decomisaba la mercadería que ingresaba fuera de registro. Por otro lado, si bien había acuerdos comerciales entre naciones, los corsarios no dudaban en apresar los barcos y apropiarse de las mercaderías.

Los géneros asiáticos eran los preferidos para ser introducidos en América fuera de registro, y las pieles y cueros de animales lo eran para su salida. Los géneros asiáticos se preferían a pesar de su menor calidad por su bajo costo. Esto provocaría, en 1806, la saturación del mercado y la queja de los comerciantes (Mazzeo 1998: 141). En cuanto a los productos decomisados, se encontraban desde pellejos de lobo, barbas de ballena, hasta géneros asiáticos y loza china. ${ }^{20} \mathrm{Si}$ bien las cantidades decomisadas son ínfimas con relación a la magnitud que pudo haber alcanzado el comercio ilícito en épocas coloniales, nos permiten apreciar que algo de lo extraído ilegalmente se decomisaba y a la vez demostrar la doble política de la Corona frente al contrabando, dado que los mismos funcionarios intervenían en él. Desde arribadas forzosas a denuncias hechas por las autoridades, para quedarse luego con los productos como premio por la acción, hasta el pago de una franquicia que dejaba libre a los infractores; todo fue posible en este juego de relaciones entre el poder del Estado, las necesidades apremiantes de la Corona y los intereses particulares de los comerciantes.

La guerra contra Napoleón en el territorio español acrecentó el comercio ilícito con América, dado que se perdió el control que tanto quería mantener la Corona y muchas naves fueron apresadas incluso por corsarios particulares.

20 En el año 1803 se decomisaron 13 mil pellejos de lobo, 220 barbas de ballena y 50 pellejos de gato marino de la fragata anglo americana La Mars por un valor de 57.945 pesos y en el mismo año arribaba al puerto del Callao la fragata anglo americana Clothier procedente de Baltimore con un cargamento cuyo valor era 495.617 pesos, y el capitán solicitó al virrey marqués de Osorno que dejara nula la sentencia por comiso del cargamento. En el año 1806 se decomisaron seis cajones de géneros asiáticos transportados en el San Francisco de Asis; al año siguiente en la fragata Palaz se decomisaron 127 piezas de loza china por valor de 12.405 pesos; Notas de 1803, del 30 de septiembre de 1806, del 20 de noviembre de 1806 y 31 de octubre de 1807, AGI, Lima 1474. 
El 11 de junio de 1813, en el puerto de Piura, José Manuel Polo había embarcado en el paquebote Nuestra Señora de las Mercedes, con dirección a Paita, 54 tercios en cajones y baúles que contenían géneros y ropas fuera de registro. Esta embarcación fue aprehendida en la ensenada de Tumbes por el corsario Santa Teresa. Los géneros se estimaron en 28.827 pesos, y se remataron de acuerdo a las instrucciones dadas para estos casos. Luego, tanto el capitán del buque como los armadores reclamaron este auto, puesto que había una real orden de 1806 en la cual se disponía que las presas de contrabando y sus cargamentos que se hacían en el mar debían adjudicarse a ellos, con inclusión de la parte correspondiente al fisco, que se entregaba a los guardacostas. Esto, como vemos, contribuía a interesar a los particulares a armarse en corso, pero las recaudaciones fiscales se reducían notoriamente. Es por ello que la Corona debió buscar alternativas. ${ }^{21}$

Hacia 1814, el Pacífico fue escenario de la guerra entre realistas e independistas y la incursión de navíos corsarios al mando de Guillermo Brown en la región se intensificó. Brown contaba con cuatro naves, Hércules, Halcón, Trinidad y Uribe, y, si bien eran naves mercantes, su destino era proteger los puertos desde Talcahuano hasta Guayaquil y debilitar las fuerzas navales realistas para preparar el camino para el ingreso de la armada libertadora. ${ }^{22}$ Esta situación perturbó las relaciones comerciales entre España y América, y la Corona debió buscar soluciones. Una de ellas fue la decisión de permitir el comercio libre con Inglaterra.

\section{Una nueva franquicia para Inglaterra, el comercio libre}

\section{Una negociación ambigua}

La necesidad de la Corona de solventar los gastos de dos guerras obligaba a reconsiderar los principios que habían regido el comercio durante la Colonia. España buscaba a través de sucesivos gobiernos un modo de conciliación. Estas conciliaciones incluían ofertas de amnistías, perdón, sobornos, reformas agrícolas e industriales y el muy difundido uso de la fuerza militar. Además de otras opciones sugestivas,

21 Esteban Fernández de León al virrey del Perú sobre el incidente en la ensenada de Tumbes, Sevilla, 20 de noviembre de 1809, AGI, Lima 1474.

22 Guerra Martinière (1982/83); entre 1815 y 1824 el corso insurgente apresó 141 buques. 
entre las cuales la más controversial y la más rechazada por aquellos que argüían la ruina para la península -especialmente los integrantes del Consulado- fue la de garantizar el comercio libre internacional a las provincias de América (Costeloe 1981: 209-234). Pero esto era una necesidad: el erario estaba cada vez más debilitado y eran acuciantes las necesidades de obtener dinero y armas para continuar dos guerras, una en América y otra en la misma península. Ello condujo a las autoridades españolas a pensar en aprobar el comercio libre con Inglaterra.

Ya se había debatido en 1810 un decreto por el cual se autorizaba a los puertos americanos a abrirse al comercio libre. Cuando se hablaba de "comercio libre" no se tomaba en cuenta a todas las naciones, sino específicamente a Inglaterra, por un determinado número de años y bajo una estricta regulación. Por otro lado, la capacidad naviera de España se había reducido y no podía afrontar las necesidades de los americanos. Los ingleses, por su parte, necesitaban metálico para resistir a la invasión francesa. En una palabra, había una "coalición de intereses". Tanto España como Inglaterra se beneficiarían de entablar relaciones comerciales. Inglaterra podría vender sus productos, América habría de exportar los suyos, España incrementaría sus beneficios económicos (Costeloe 1981: 217-219). Era imperioso encontrar una política de solución a los urgentes problemas de la península.

En 1814 regresó el rey Fernando VII y los reformadores quedaron prácticamente sin lugar. Con la restauración del rey se impuso la vieja política de restricciones. Sin embargo, Inglaterra tenía toda la intención de actuar como intermediaria en el conflicto americano si se le permitía el comercio libre con las colonias, a lo cual se oponían tenazmente los comerciantes de Cádiz. En Madrid había dos grupos, uno que se manifestaba por la aplicación de la fuerza militar, y otro, más moderado, que pretendía aplicar medidas reformadoras que resolvieran los problemas con las colonias.

El tema del comercio libre volvía nuevamente al tapete y en reuniones sucesivas con el Consejo de Indias se llegó a la conclusión de que - para no perderlo todo- una posible solución sería permitir la interposición de Inglaterra para la pacificación de la América del Sur y proporcionar algunas ventajas comerciales a cambio (Costeloe 1981: 217-219). Iniciada la guerra de Independencia en las colonias, la situación comercial se perturbó aún más y ello derivó en la necesidad de ceder más beneficios a los extranjeros. En el Perú, la urgencia de re- 
cabar dinero para armar los barcos de guerra había convencido al virrey Joaquín de Pezuela de abrir el comercio con los ingleses, aunque el Consulado de Lima, al igual que el de Cádiz y el de Veracruz, se oponía a ello. Por su parte, tampoco el virrey anterior, Fernando de Abascal, estaba muy de acuerdo y elevó un informe al rey sobre su postura frente al proyecto que Pezuela quería aplicar respecto al comercio entre el puerto del Callao e Inglaterra.

En su disertación a la Corona en contra de tal medida, Abascal comentaba que el erario de Lima siempre había sido escaso, y que a raíz de la caída del virreinato del Río de la Plata en poder de los ingleses en 1806, tuvo que hacer frente a dicho conflicto enviando auxilios a dicha zona. Añadió que ello produjo un déficit en el erario de cinco millones de pesos y que si realmente había podido hacer frente a todos los gastos del virreinato fue gracias a los cuantiosos donativos entregados por el generoso vecindario. Pero en ese momento la situación se había agravado a causa de la guerra, que prácticamente paralizó el comercio, y por la pérdida de Chile. Por lo tanto, en ese contexto, le parecía factible adoptar el comercio libre con los ingleses, pero no por dos años sino por menos tiempo, pues, refiriéndose a los ingleses, decia: "no necesitan mucho para arruinar la industria del país". Sin embargo, mantuvo ciertas reticencias al respecto y agregó: "Tengo por muy arriesgado cualquier tratado de comercio que se calibre con ellos pues sin que pueda percibirse el mecanismo de esta máquina siempre le aplican un tornillo o resorte reservado que apretándole o aflojándolo la inclinan a su favor. ${ }^{.23}$

Continuando con su alegato, explicaba que la medida traería consigo la queja de los 15 a 20 mil artesanos que en Lima vivían de su trabajo, de los cuales cinco a seis mil eran milicianos y que con un tratado de tal magnitud se inundaría el país no sólo de tejidos sino de ropas hechas, zapatos, botas, muebles y carruajes a precios muy inferiores y ¿qué harían estos milicianos con los brazos armados y sin alivio para alimentar a su familias? En una palabra, pensaba que podrían producirse levantamientos y revueltas internas. Concluyó su disertación repitiendo que el comercio libre con los ingleses era peli-

23 Informe del virrey marqués de la Concordia sobre el proyecto del comercio libre [...] propuesto por el actual virrey Joaquín de la Pezuela, AGI, Lima 1550: Expedientes del Consulado, 1812-1819. 
grosísimo, en el Perú más que en otra parte, y que no debía permitirse, sino como un último y desesperado recurso. Los únicos datos que podía aportar como otra posible solución eran sobre el laboreo de algunas minas por cuenta de la Real Hacienda cuyo proyecto, en caso de llegarse a planificar y ser dirigido por manos inteligentes y fieles, podía producir ingentes intereses. Concluía diciendo que era partidario de que los permisos de expediciones mercantes que concediera el virrey fueran para Asia y concedidos a españoles, prohibiendo los géneros que pudieran perjudicar a la industria del país. ${ }^{24}$

\section{La posición del Consulado de Lima frente al comercio libre}

La institución que había actuado como banco financiero de la Corona no podía estar de acuerdo con permitir negociar con los ingleses. En 1814 el Consulado de Lima envió una relación de los donativos y servicios prestados al rey y al Estado desde 1777 hasta dicho año. De acuerdo al citado documento, se había prestado de los ramos que administraba la suma de 964.208 pesos y los capitales tomados a interés ascendían a 5.035.824 pesos; por donativos correspondían 2.636.255 pesos hasta 1804 , y tomando el año 1805 correspondían 3.363.776 pesos, a lo que habría que añadir los 102.352 pesos que habían contribuido los individuos del comercio. ${ }^{25}$ Esta suma había llegado, en el año 1815 , a 6.001 .280 pesos, es decir que en diez años se había duplicado la cantidad aportada en 38 años. ${ }^{26}$

No obstante la postura del Consulado, el 22 de julio de 1818 se decidió otorgar el comercio libre con los ingleses por el término de dos años pagando un $12 \%$ sobre los derechos comunes. El 23 de julio se llamó a una junta extraordinaria y, luego de deliberar, se decidió entregar al virrey 500.000 pesos como contribución, por los cuales se debía pagar el $6 \%$ de interés tanto a los comerciantes que estaban matriculados como a los que no lo estaban. El pago al virrey se realizaría en mesadas de 100.000 pesos. ${ }^{27}$ El 22 de octubre del mismo año, la

24 Informe del virrey marqués dela Concordia, Madrid, 29 de junio de 1819, AGI, Lima 1550.

25 Razón de los empréstitos contraídos por este Tribunal con motivo de los donativos y servicios hechos al rey y al Estado desde el año 1777 hasta el presente de 1814, AGI, Lima 1551: Documentos del Consulado, 1820-1826. Informe del Consulado de Lima al virrey del Perú, AGI, Indif. Gen. 2472. 
Junta de Arbitrios establecía que el Consulado debía proporcionar 200.000 pesos al contado para sostener los derechos del trono y la integridad de aquellos dominios, además de aportar 117.000 pesos por mes para cubrir las atenciones a que no llegaba el erario. El Consulado aceptó y desechó la propuesta de traficar con buques ingleses y con Río de Janeiro. ${ }^{28}$

En una palabra, el control comercial y el poder que tenía el Consulado eran tales que podía revocar las medidas tomadas por la Corona llegada la decisión de comerciar con ingleses, para lo cual eran capaces de hacer los más grandes sacrificios. Manuel Gorbea, como representante del Consulado de Lima, enviaba al rey, en febrero de 1819 , una nota en la cual solicitaba que no se permitiese el comercio libre con Inglaterra y a propuesta de la Junta ofrecía un donativo de 735.000 pesos. ${ }^{29}$ En total, para 1820 , las sumas entregadas por el Consulado a la Corona para auxiliarla llegarían a 7.306.244 pesos. $^{30}$

No obstante, en 1819, el virrey Pezuela propuso el comercio libre con Inglaterra, cuyos motivos eran el erario suficientemente escaso y la necesidad de aliviar los padecimientos como la paralización del comercio. A esto se opuso el Consulado, a lo que se aunó el marqués de la Concordia, tomando partido a favor de los artesanos. Pezuela atribuía la oposición del Consulado al comercio libre a "algún monopolista que piensa en enriquecerse a costa de la necesidad pública [...]. Y los que fomentaron y sostienen el proyecto son muy pocos, egoístas que cuentan cargar con las comisiones por entender el idioma inglés y por sus relaciones con Inglaterra". ${ }^{31}$

La postura de Pezuela fue muy distinta a la de Abascal. Las necesidades apremiantes de la guerra lo llevaron a adoptar el sistema de concesiones y beneficios mutuos y no dudó en entregar licencias a extranjeros si ello redundaba en beneficios pecuniarios. En un oficio de diciembre de 1819 solicitaba al embajador español en Londres el suministro de 160 piezas de artillería de hierro, concediendo a los que

28 Nota de la Junta de Arbitrios al Consulado de Lima, 22 de octubre de 1818, AGI, Indif. Gen. 1359.

29 Carta del representante del Consulado al rey, 13 de febrero de 1819, AGI, Lima 1550 .

30 Nota del Consulado elevada al rey sobre el estado del Perú y sus causas, 5 de octubre de 1820, AGI, Indif. Gen. 313: Gobernación de Ultramar.

31 Nota del marqués de la Concordia, Madrid, 29 de junio de 1819, AGI, Lima 1550: Expedientes del Consulado. 
las condujesen la facultad de introducir en el Perú, en forma proporcional, efectos mercantiles extranjeros con la sola obligación de pagar los derechos reales y municipales como si fuesen nacionales y provinieran de Cádiz. ${ }^{32}$ Debido a la gran cantidad de fragatas extranjeras que entraron en el Callao, Pezuela debió responder y dar cuenta de las razones que lo llevaron a permitir el ingreso de dichos barcos. En ese informe Pezuela expresaba que sólo lo llevó el ánimo de "defender estos dominios".

En 1817 la fragata francesa Bordelais, procedente de Burdeos con destino "a las costas del noroeste e India Oriental", arribó al puerto de Valparaíso por la necesidad de reemplazar víveres y, cuando estaba en tratos con las autoridades para vender parte del cargamento, sucedieron los hechos de Chacabuco. El teniente del navío Camile Roquefuevill socorrió al gobernador de Valparaíso con 211 fusiles que traía a bordo y logró extraer algunos emigrados y traerlos al Callao, donde pudo obtener los mencionados víveres. Como no tenía numerario, solicitó comerciar y el virrey accedió a la descarga de sus productos -cuyo importe ascendía a 45.000 pesos- bajo la condición de no sacar retorno alguno en numerario y pagar los derechos y aranceles establecidos en el decreto del libre comercio. Lo mismo sucedió con los bergantines anglo americanos Beaver y Canton, que llegaron con parte de las tropas que evacuaron de Talcahuano. ${ }^{33}$

\section{La venta de armas, un beneficio mutuo}

La venta de armas era también una de las alternativas que se ofrecían a los ingleses para obtener franquicias comerciales, y eran los buques angloamericanos los que se ocupaban mayormente de ello.

En 1818 la goleta angloamericana Shelby procedente de Nueva York, había llegado al Callao con 3.344 fusiles con sus bayonetas, 1.285 sables, 410 pares de pistolas y 30.000 piedras de chispas, cuyo destino era originariamente Panamá. Al final se negociaron en Lima por encontrarse el virrey escaso de armamento y con pocas esperanzas de que el gobierno se lo enviase, a pesar de las reiteradas veces que lo

32 Oficio al embajador español en Londres, 7 de junio de 1819, AGI, Lima 1550.

33 AGI, Lima 759. También llegaron las fragatas rusas Kutusow y Suwarow de cuyo cargamento no se da información. Documentos del virrey a la vía reservada de Abascal, 1818, AGI, Lima 759. 
había solicitado. Estos barcos, a su vez, proporcionaban información sobre las noticias de los insurgentes. ${ }^{34}$

Por esa misma fecha, Pezuela, el virrey del Perú, llevó a cabo una contratación con la fragata inglesa ballenera Apost, para comprar algunas armas. En la misma se estipulaba la entrega de 4.000 fusiles, pistolas y sables de Inglaterra o Francia y la autorización de ingresar géneros por un valor de 200.000 pesos que, a su entrada en el virreinato del Perú, pagarían los mismos derechos que los productos que vinieran de Cádiz, es decir, como si fueran españoles. La expedición fue concedida a José Arismendi. Para facilitarla, éste llevaría, junto con el real permiso, una "patente de corso en blanco", lo cual funcionaría como una especie de salvoconducto ante los inminentes conflictos en el mar que se suscitaban en dicha época. En 1820 el comisionado en Londres explicaba que en aquel tiempo no se habría podido llevar a cabo la contrata (no se especifica por qué) y que acababa de recibir a un representante de Arismendi que lo instaba a acelerar la expedición, por ser esta "de mucha utilidad para convoyar a buques mercantes que salen de aquel puerto para los demás puntos de la costa". La tardanza era atribuida al temor que tenían a los corsarios de Cochrane, y se explicaba que el motivo de acelerar ahora la expedición provenía de las recientes instancias que había recibido de Lima de un agente especial y por ser ésta de mucha utilidad en esos tiempos. ${ }^{35}$

Otra embarcación procedente de Río de Janeiro, la zumaca portuguesa llamada La Brillante Magdalena, que había ido a Valparaíso cargada con 370 quintales de sebo, 49 tercios de hilos de vela, y con 24.000 pesos en numerario también debió trasladarse al Callao cuando acontecieron los sucesos en Talcahuano. ${ }^{36}$

Para octubre de 1818 había arribado al Callao el barco Macedonia y su capitán propuso venderlo al costo de su construcción, siempre que se le permitiese expender su reducido cargamento. El virrey se dirigió entonces al Consulado para exponer la necesidad que tenía la

\footnotetext{
34 Documentos del virrey a la vía reservada de Abascal, 1818, AGI, Lima 759.

35 Nota sobre una contrata del virrey del Perú, 13 de septiembre de 1818, AGI, Lima 1551: Documentos del Consulado, 1820-1826; Nota del duque Fernando de Quiroga, Palacio, 9 de febrero de 1820, ibidem; AGI, Lima 1550.

36 Nota del virrey del Perú al rey sobre los motivos que tuvo para permitir la venta de productos traídos en barcos extranjeros, AGI, Lima 1550, nota 327; también en AGI, Lima 759.
} 
Marina de un buque de tal ligereza, pertrechado con 20 piezas, y al mismo tiempo al tribunal para que se hiciese cargo de la compra total, con la obligación de ceder a la Real Hacienda el casco y las especies que necesitare para vestuario de la tropa. Pero el Consulado se rehusó a ello y por lo tanto tuvo que denegar el permiso, aun a costa de correr el riesgo de que dicho barco recurriese al contrabando para realizar su negocio ya que no era fácil impedirlo, "dado que es prácticamente imposible cuidar las extensas costas y la cantidad de caletas que posee la costa peruana". ${ }^{37}$

De esta manera vemos como la doble política que la Corona y las autoridades en América llevaban a cabo estaba en función de las necesidades. Mientras que Abascal había sido un acérrimo defensor de los derechos monopólicos, Pezuela no dudaba en permitir la entrada de barcos extranjeros si veía que podía sacar un beneficio económico que le permitiera costear la guerra en la cual estaban empeñados contra los patriotas. Ello le costó el puesto, porque fue destituido por un golpe militar dado por José de la Serna y conocido como el "motín de Aznapuquio". Para los españoles en América había llegado muy lejos y también para el Consulado, que rechazaba en todo momento negociar con firmas extranjeras, especialmente inglesas, a pesar de que la Corona había firmado un acuerdo con el gobierno británico. Tolerancia, libertad y a la vez restricciones e imposiciones eran las características que tomaba el comercio con América en esta época tan convulsiva.

\section{El Consulado frente a la República}

Un informe elevado al rey el 31 de agosto de 1821 por el procurador general del Consulado de Comercio de Lima, Antonio Real de Azúa, comenta sobre el deplorable estado del comercio debido a la insurrección de Río de la Plata y del escandaloso contrabando que se realizaba por los puertos de Payta, Guayaquil y otros, a pretexto del permiso concedido por la junta central para el comercio de Panamá por Chagre y Portobelo, sugiriendo, por lo tanto, que no se permitiera el arribo de embarcaciones de Panamá. Hace referencia además a la llegada de barcos franceses y rusos, señalando que debido a la cantidad de permi-

37 Carta firmada por el virrey Joaquín de la Pezuela, 3 de noviembre de 1818, AGI, Lima 759: Documentos del virrey por la vía reservada a Abascal, 1818. 
sos que se admitían con el nuevo gobierno, el comercio se halla en estado calamitoso.

Por otro lado, consideraba que los ingleses no debían sacar partido de la situación puesto que las haciendas quedaron prácticamente devastadas por las tropas de los insurgentes, porque sacaron de ellas a los negros ofreciéndoles la libertad que no pedían. Guayaquil se independizó lo mismo que Trujillo, sublevada por su intendente Torre Tagle. En tal estado, no pueden recibir surtido de los géneros de consumo, como no sea a través del "dañoso y estéril" contrabando: "Nuestros comerciantes no pueden recibir mercaderías en naves españolas, las que llegan a un mar inundado de piratas, con la falta de provisión y recursos para mantener el ejército y los demás funcionarios del Estado, y el alimento del comercio y el exhausto erario no pueden ni siquiera pagarse los réditos de los cuantiosos capitales adelantados en obsequio de la patria y por lo tanto piden navíos que limpien los mares de insurgentes para salvar a los fieles españoles y a las ricas y vastas posesiones del Perú." 38

El 12 de abril de 1822 un oficio dirigido al cónsul de Hamburgo por el general San Martín permitía el comercio libre, únicamente con los puertos del Callao y Huanchaco, y la entrada de todas las banderas, estableciendo el pago de un $20 \%$ sobre todos los géneros que ingresaban en buque extranjero, el $18 \%$ sobre los productos que ingresaban en buques de Chile, Río de la Plata y Colombia, y el 16\% los buques peruanos. Además, quedaban abolidas las aduanas interiores, pudiendo circular sin necesidad de guías, excepto el oro y la plata, los cuales deben pagar a su extracción cualquiera sea la bandera el $5 \%$ la plata y el $2 \frac{1}{2} \%$ el oro. Se prohibía la extracción de oro y plata no acuñado y se ordenaba que los productos del Perú que salieran en buques extranjeros pagaran el $4 \%$ y el 3,5\% si salían en buques con bandera de Chile, La Plata y Colombia, mientras que, si eran buques peruanos, pagarían el $3 \%{ }^{39}$

Las necesidades apremiantes del Gobierno republicano lo obligaron a solicitar nuevos préstamos a la élite mercantil. El tribunal había sido disuelto, una Junta de Arbitrios actuaba en su poder. En 1823 el

\footnotetext{
38 Informe de Antonio Real de Azúa al rey, AGI, Indif. Gen. 313. Este documento ha sido publicado por Pacheco Vélez (1957).

39 Oficio dirigido al cónsul de Hamburgo por el general San Martín sobre el comercio libre, 12 de abril de 1822, AGI, Indif. Gen. 313.
} 
Gobierno solicitó un cupo para la financiación de la guerra. Por lo cual, algunos comerciantes solicitaron que el mismo se pagara mitad en pesos y mitad en productos, porque no estaban las condiciones para solventar dichas cargas. ${ }^{40}$ San Martín solicitó al Consulado un cupo de 150.000 pesos, que fue pagado por la élite mercantil.

Había triunfado el libre comercio y con ello, la fuerza del Consulado se disolvió, quedando éste totalmente desarticulado. Sin embargo nuevos conflictos se producirían durante la República.

\section{Conclusión}

Con relación al sistema mercantil, la ambigüedad política de la Corona española a fines del periodo virreinal respondió a la necesidad de enfrentarse a los problemas suscitados por coyunturas políticas internacionales.

El comercio con neutrales, por un lado, benefició a algunos comerciantes coloniales, pero mucho más a los extranjeros, quienes fueron los receptores de los metales preciosos peruanos y lograron lo que tanto querían desde antaño, comerciar directamente con América. Se beneficiaron muchas firmas extranjeras, entre ellas la casa inglesa Gordon y Murphy. Se amplió el mercado internacional, nuevos puertos entraron en el concierto económico. Veracruz, La Habana, Boston y Filadelfia se incorporaron a negociar con México, Cartagena, Lima y Buenos Aires. Y fueron las élites comerciales las que se dedicaron a este negocio de gran magnitud.

El contrabando siguió siendo un medio de introducir las mercaderías aun en contra de la legislación. Los tres vértices del triángulo comercial eran: la península, el mercado americano y el comercio extranjero. Cada uno sacaba provecho de ello. ¿Quién se perjudicaba? Pues las antiguas oligarquías mercantiles que seguían bregando por la exclusividad, por mantener, a costa de cualquier sacrificio, aquellos principios básicos del sistema mercantil: la exclusividad y la xenofobia.

La acción de los corsarios insurgentes, a partir de 1814, acrecentó la situación crítica del comercio legal. En los diez años que siguieron, hasta la consumación de la independencia, se llegaron apresar

40 Nota del Consulado elevada al virrey sobre la necesidad de financiar el cupo de guerra, AGNP, Consulado (H4, 1556). 
141 embarcaciones con mercaderías y provisiones para los puertos americanos. Esto acrecentó la desconfianza y el temor de los comerciantes de traficar en naves españolas, lo que incentivó el comercio en buques neutrales.

A la política de tolerancia, impartida por los gobiernos para solventar los gastos de guerra, se opusieron los consulados tanto de Cádiz como de Lima y México. Esta política no debe interpretarse como proteccionista, sino más bien como deseosa de mantener los privilegios que se habían adquirido mucho antes. El Consulado de Lima se enfrentó al comercio con neutrales, como al comercio libre con Inglaterra, pero también hubo comerciantes que lograron sacar provecho de ello.

La flexibilidad de la política española tenía como objetivo proteger sus intereses y su imperio. Durante 300 años lo había logrado, pero las nuevas directrices que se pusieron en marcha en el comercio internacional dividieron al mundo en dos. Una parte luchaba por obtener nuevos mercados, empujados por el proceso de revolución industrial, marcando así el comienzo del capitalismo moderno; otra parte se aferraba a las prácticas tradicionales y defendía los sistemas de exclusividad y privilegios típicos del monopolio.

Comercio con neutrales, contrabando, comercio libre con ingleses fueron factores con los cuales tuvo que enfrentarse el Consulado en defensa de sus intereses. La independencia fue el último golpe que recibió está institución, que quedó totalmente desarticulada por un periodo de tiempo, porque a partir de 1829 les fueron devueltas sus atribuciones. No obstante, dejó de cumplir con las funciones gremiales y judiciales y su actividad quedó reducida a un simple organismo representativo del comercio (Smith 1961: v-lvi).

Hacia 1830 se restablecieron sus atribuciones, como así también las diputaciones en las capitales de los departamentos, cuyos representantes legislaban en conflictos menores, dado que en lo contencioso dependían del tribunal superior del Consulado de Lima. No obstante, durante mucho tiempo no tuvo el país un Código de Comercio y siguieron rigiéndose por las Ordenanzas de Bilbao, lo que indica que el tránsito hacia la República no significó en modo alguno un cambio radical en la legislación mercantil. Establecer las nuevas relaciones de poder entre la institución y el gobierno republicano es tema de una próxima investigación. 